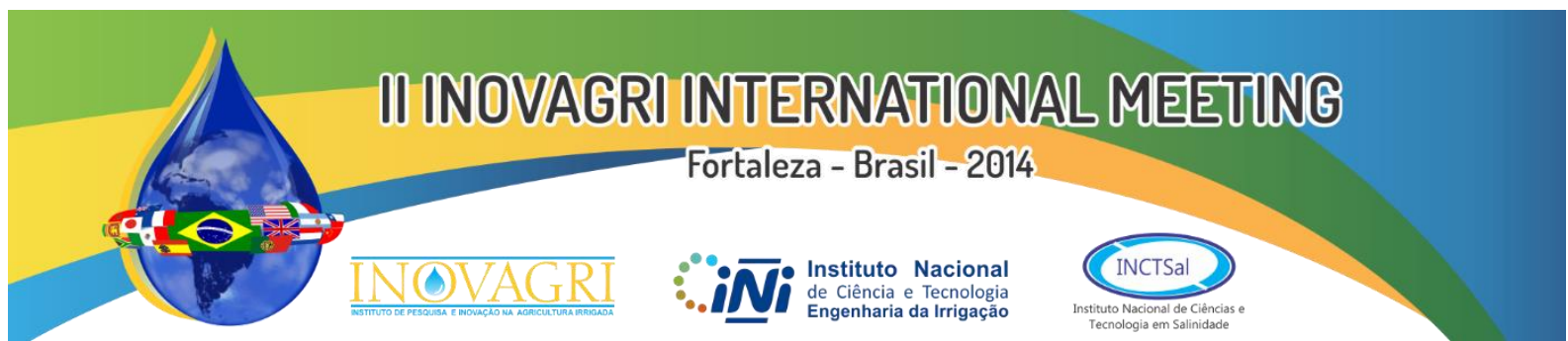

http://dx.doi.org/10.12702/ii.inovagri.2014-a158

\title{
PRODUTIVIDADE E EFICIÊNCIA DE UTILIZAÇÃO DA ÁGUA DO MORANGUEIRO EM CULTIVO HIDROPÔNICO FECHADO UTILIZANDO SUBSTRATO DE FIBRA DE COCO ${ }^{1}$
}

\author{
F. R. de Miranda ${ }^{2}$, V. B. da Silva ${ }^{3}$, F. S. R. dos $\operatorname{Santos}^{4}$, C. F. B. da Silva ${ }^{5}$, A. G. Rosseti ${ }^{6}$, I. Soares ${ }^{7}$
}

RESUMO: Avaliou-se a produtividade e a eficiência de utilização da água do morangueiro cultivado em dois tipos de sistemas hidropônicos fechados, na serra da Ibiapaba-CE. Os tratamentos foram constituídos dos sistemas de cultivo hidropônicos fechados em calhas e em sacos de cultivo, contendo substrato de fibra de coco e duas cultivares de morango (Festival e Oso Grande). O delineamento experimental foi em blocos casualizados, com os tratamentos de sistemas de cultivo arranjados em faixas e cinco repetições. Os sistemas de cultivo hidropônicos em calhas e em sacos apresentaram produtividades semelhantes $(6425 \mathrm{~g}$ $\mathrm{m}^{-2}$ e $6125 \mathrm{~g} \mathrm{~m}^{-2}$, respectivamente). Os maiores valores de produtividade e de eficiência de utilização da água foram obtidos com a cv. Festival, no sistema de cultivo em calhas $\left(7405 \mathrm{~g} \mathrm{~m}^{-2}\right.$ e $12,7 \mathrm{~g} \mathrm{~L}^{-1}$, respectivamente).

PALAVRAS-CHAVE: Fragaria $x$ ananassa, hidroponia, fibra de coco.

\section{YIELD AND WATER USE EFFICIENCY OF STRAWBERRY IN CLOSED HYDROPONIC SYSTEMS WITH COCONUT FIBER SUBSTRATE}

SUMMARY: We evaluated the yield and water use efficiency of strawberry grown in two types of closed hydroponic systems at the Serra da Ibiapaba-CE, Brazil. The treatments consisted of closed hydroponic systems in gutters and in slabs, with coconut fiber substrate, and two strawberry cultivars (Festival and Oso Grande). The experimental design was a randomized strip plot design, with the hydroponic systems set in the strips and five replicates. The two closed hydroponic systems tested showed similar yields $\left(6425 \mathrm{~g} \mathrm{~m}^{-2}\right.$ and $6125 \mathrm{~g} \mathrm{~m}^{-2}$, respectively). The highest values of yield and water use efficiency were obtained for cv. Festival, grown in gutters (7405 $\mathrm{g} \mathrm{m}^{-2}$ and $12.7 \mathrm{~g} \mathrm{~L}^{-1}$, respectively).

KEYWORDS: Fragaria $x$ ananassa, hydroponics, coconut fiber.

\section{INTRODUÇÃO}

O cultivo convencional do morangueiro (no solo) apresenta limitações relacionadas à incidência de fitopatógenos e seu controle com produtos químicos fumigantes e às dificuldades ergonômicas do cultivo em canteiros, que podem causar danos à saúde dos trabalhadores (Godoi et al., 2009). O uso de sistemas de cultivo sem solo (hidropônicos), em ambiente protegido, é apontado como uma tendência para a cultura do morangueiro. Uma vez que o cultivo é feito em bancadas acima do nível do solo, o trabalho é facilitado e menos insalubre, elimina-se o uso de produtos destinados à desinfecção do solo, há redução da ocorrência de doenças foliares, e consequentemente da aplicação de defensivos. Além disso, ocorre uma melhora da qualidade dos frutos, tanto do ponto de vista organoléptico, como de

\footnotetext{
${ }^{1}$ Pesquisa financiada pelo Banco do Nordeste do Brasil

${ }^{2}$ Ph.D., Pesquisador, Embrapa Agroindústria Tropical, R. Dra. Sara Mesquita, 2270, Fortaleza-CE, Brasil, CEP 60511-110. Email: fabio.miranda@embrapa.br

${ }^{3}$ Estudante de Agronomia, Universidade Federal do Ceará, Fortaleza-CE.

${ }^{4}$ Eng. Agrônomo, Mestrando em Fitotecnia, Universidade Federal do Ceará, Fortaleza-CE.

${ }^{5}$ Doutor, Pesquisador, Embrapa Agroindústria Tropical, Fortaleza-CE.

${ }^{6}$ Doutor, Pesquisador, Embrapa Agroindústria Tropical, Fortaleza-CE.

${ }^{7}$ Prof. Doutor, Depto. de Solos, Universidade Federal do Ceará, Fortaleza-CE.
}
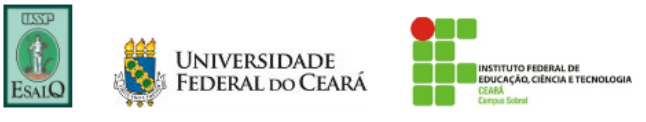
contaminantes químicos e microbiológicos (EMBRAPA, 2005). Nesse sentido, alguns estudos tem sido realizados no Brasil utilizando sistemas hidropônicos do tipo Nutrient Film Technique (NFT) (Fernandes Júnior et al., 2002; Bonnecarrère, 2002) ou com substratos (Fernandes Júnior et al., 2002; Godoi et al., 2009).

Os sistemas hidropônicos podem ser de dois tipos: a) fechados, estáticos ou recirculantes, quando a solução nutritiva que passa pelas raízes volta ao depósito de origem e, b) abertos, quando a solução aplicada ao ambiente radicular não retorna à origem (Fernandes Júnior et al., 2002). A maior parte dos sistemas de cultivo sem solo do morangueiro emprega algum tipo de substrato e é do tipo aberto. Os substratos permitem maior controle do teor de oxigênio e maior inércia térmica das raízes, quando comparados com os sistemas hidropônicos do tipo NFT. Em virtude da poluição do solo, o descarte da solução nutritiva em sistemas hidropônicos abertos vem sendo restringido em países da Europa como a Holanda e outros (Gimenez et al., 2008).

Apesar do cultivo sem solo ser uma tendência para a cultura do morangueiro, há necessidade de desenvolver sistemas que combinem alta produtividade, qualidade dos frutos, baixo custo e reduzido impacto ambiental. Esses sistemas devem ser do tipo fechado (sem descarte de solução nutritiva) e empregar substratos com boa disponibilidade e preços acessíveis na região (Gimenez et al., 2008). Sistemas hidropônicos fechados, utilizando como substrato a casca de arroz carbonizada, foram testados com sucesso no cultivo do morangueiro por Godoi et al. (2009) no Rio Grande do Sul.

Nas regiões Norte e Nordeste do Brasil um dos substratos com maior disponibilidade é a fibra de coco. Esse material é um excelente substrato orgânico devido às suas propriedades de retenção de umidade, aeração do meio de cultivo e estimulador de enraizamento (Nunes, 2000; Carrijo et al., 2004).

Este trabalho teve por objetivo avaliar a produtividade e a eficiência de utilização da água do morangueiro cultivado em dois tipos de sistemas hidropônicos fechados e com substrato de fibra de coco.

\section{MATERIAL E MÉTODOS}

O experimento foi realizado no período de maio de 2012 a janeiro de 2013, em uma propriedade particular localizada em Ibiapina-CE (latitude $3^{\circ} 58^{\prime} \mathrm{S}$, longitude $40^{\circ} 52^{\prime} \mathrm{O}$ e altitude $920 \mathrm{~m}$ ). Os tratamentos foram constituídos de dois sistemas de cultivo hidropônicos fechados (em calhas e em sacos) e duas cultivares de morango (Festival e Oso Grande). O delineamento experimental foi em blocos casualizados, com os tratamentos de sistemas de cultivo arranjados em faixas e cinco repetições.

Nos sistemas hidropônicos foram utilizadas duas bancadas de madeira com $0,8 \mathrm{~m}$ de altura, 1,0 $\mathrm{m}$ de largura e 12,0 $\mathrm{m}$ de comprimento, espaçadas de $0,8 \mathrm{~m}$ entre si. As bancadas foram instaladas sob túnel alto com estrutura tubular em aço galvanizado, coberta com filme plástico leitoso de $150 \mu \mathrm{m}$, com $3 \mathrm{~m}$ largura e 2,5 m de altura. Em uma das bancadas foram instaladas três fileiras de calhas modelo Auto Compensadora Pequena (Hidrogood Horticultura Moderna Ltda.), com dimensões de 4,0 $\mathrm{m}$ de comprimento, $0,22 \mathrm{~m}$ de altura e $0,17 \mathrm{~m}$ de largura. Cada calha foi preenchida com $26 \mathrm{~L}$ de substrato de fibra de coco Golden Mix Misto Tipo 80 (Amafibra Fibras e Substratos Agrícola da Amazônia Ltda). Na outra bancada foram dispostas duas fileiras de 10 sacos de cultivo feitos de plástico branco-preto, com dimensões de 1,2 $\mathrm{m}$ de comprimento, $0,22 \mathrm{~m}$ de largura e $0,12 \mathrm{~m}$ de altura cada, contendo substrato de fibra de coco (BM Bioengenharia Ambiental Ltda).

No tratamento do cultivo em calhas foi utilizado o espaçamento de $0,30 \mathrm{~m}$ entre plantas e 0,33 $\mathrm{m}$ entre fileiras, totalizando 12 plantas por parcela. No cultivo em sacos foram utilizados dois sacos de cultivo por parcela, espaçados de $0,5 \mathrm{~m}$ entre si. Em cada saco foram plantadas oito mudas, no espaçamento de $0,15 \mathrm{~m}$ entre fileiras e $0,30 \mathrm{~m}$ entre plantas na fileira, em triângulo, totalizando 16 plantas por parcela.

O plantio foi realizado em 23/05/2012 utilizando mudas de raiz nua. Os tratos culturais foram realizados de acordo com as recomendações de Bortolozzo et al. (2007). Semanalmente foram retirados estolões e folhas senescentes ou que apresentassem sintomas de doenças foliares. Pragas e doenças foram controladas quimicamente quando necessário.

Na fertirrigação foi utilizada a solução nutritiva recomendada por Furlani e Fernandes Júnior (2004). Para sua aplicação foi utilizado um sistema recirculante, em que a solução foi bombeada a 
partir de um reservatório de fibra de vidro com $5 \mathrm{~m}^{3}$ de capacidade e aplicada por gotejamento (um emissor por planta, com vazão de $2 \mathrm{~L} \mathrm{~h}^{-1}$ ). Foram aplicados pulsos de irrigação com duração de 5 min (volume de $0,17 \mathrm{~L}$ por pulso, por planta). O número de pulsos diários variou de um por dia nos primeiros dias após o transplante das mudas a até no máximo seis pulsos por dia a partir dos 110 dias após o transplante (DAT). Os volumes de solução nutritiva excedentes à capacidade de retenção do substrato foram coletados das calhas e dos sacos de cultivo, por tubos de PVC e conduzidos por gravidade de volta para o reservatório. A cada 15 dias a solução nutritiva restante no reservatório foi descartada e substituída por uma nova solução.

As colheitas foram realizadas duas vezes por semana, de 05/07/2012 (42 DAT) até 22/02/2013 (274 DAT). Em cada colheita foram avaliados o número e a massa de frutos por parcela, utilizando uma balança eletrônica com precisão de $0,1 \mathrm{~g}$. Os dados foram submetidos à análise de variância e as médias foram comparadas pelo teste $\mathrm{F}$, ao nível de $5 \%$ de probabilidade.

\section{RESULTADOS E DISCUSSÃO}

Na Tabela 1 são apresentados os valores máximos e mínimos de $\mathrm{pH}$ e condutividade elétrica (CE) da solução nutritiva medidos durante o experimento.

Tabela 1 - Valores medidos de pH e condutividade elétrica (CE) da solução nutritiva em sistemas de cultivo hidropônico fechados em calhas e em sacos.

\begin{tabular}{lcc}
\hline & Calhas & Sacos \\
\hline pH Solução Nutritiva & $5,0-6,6$ & $5,0-6,6$ \\
pH Drenagem & $5,1-6,7$ & $5,1-6,6$ \\
CE Solução Nutritiva $\left(\mathrm{dS} \mathrm{m}^{-1}\right)$ & $1,2-1,8$ & $1,2-1,8$ \\
CE Drenagem $\left(\mathrm{dS} \mathrm{m}^{-1}\right)$ & $1,0-2,2$ & $1,1-2,2$ \\
\hline
\end{tabular}

Considerando-se a média das duas cultivares, não houve diferenças significativas de produtividade $\left(\mathrm{g} \mathrm{m}^{-2}\right)$ entre os sistemas de cultivo hidropônico em calhas e em sacos (Tabela 2). A cultivar Oso Grande apresentou produtividade inferior a cv. Festival no sistema de cultivo em calhas. Já no sistema de sacos não houve diferença significativa entre as duas cultivares.

Tabela 2 - Massa de frutos por metro quadrado $\left(\mathrm{g} \mathrm{m}^{-2}\right)$ de duas cultivares de morango em dois sistemas de cultivo hidropônico. Ibiapina-CE, 2012*

\begin{tabular}{|c|c|c|c|c|c|c|c|c|}
\hline Cultivares & Calhas & & & Sacos & & & Média & \\
\hline Festival & 7405,0 & $\mathrm{a}$ & $\mathrm{A}$ & 6568,4 & $\bar{a}$ & B & 6986,7 & $\bar{a}$ \\
\hline Oso Grande & 5444,4 & $\mathrm{~b}$ & A & 5681,6 & $\mathrm{a}$ & A & 5563,0 & $\mathrm{~b}$ \\
\hline Média & 6424,7 & $\mathrm{~A}$ & & 6125,0 & $\mathrm{~A}$ & & 6274,8 & \\
\hline $\mathrm{CV}(\%)$ & 11,8 & & & 9,9 & & & 11,3 & \\
\hline
\end{tabular}

*Médias seguidas pelas mesmas letras minúsculas nas colunas e maiúsculas nas linhas não diferem entre si pelo teste $\mathrm{F}$ ao nível de $5 \%$ de probabilidade.

Atualmente a cultivar Oso Grande é a preferida pelos produtores da região da Ibiapaba, os quais relatam que ela é uma das mais resistentes às doenças e produz frutos de tamanho e aparência adequados para o mercado de frutos in natura. Segundo Antunes \& Reisser Júnior (2007), a cv. Oso Grande é a cultivar de morangueiro de maior expressão econômica no Brasil.

As produtividades alcançadas no presente estudo são comparáveis com aquelas obtidas na Europa, em estudos com o morangueiro cultivado em sistemas hidropônicos com substratos, que segundo Gimenez et al. (2008), variam de 5 a $10 \mathrm{~kg} \mathrm{~m}^{-2}$.

Com relação a outros estudos realizados no Brasil, a produtividade máxima obtida no presente estudo $\left(7,4 \mathrm{~kg} \mathrm{~m}^{-2}\right.$ com a cultivar Festival no sistema de calhas) foi superior às obtidas em cultivos no solo na região Sul do Brasil por Virmond e Resende (2006) (5,5 e 5,7 $\mathrm{kg} \mathrm{m}^{-2}$, com as cultivares Oso Grande e Camarosa, respectivamente) e Cancian et al. (2002) $\left(1,8 \mathrm{~kg} \mathrm{~m}^{-2}\right.$ e $2,6 \mathrm{~kg} \mathrm{~m}^{-2}$, com as 
cultivares Oso Grande e Camarosa, respectivamente). Andriolo et al. (2002) obtiveram produtividade média de $4,0 \mathrm{~kg} \mathrm{~m}^{-2}$ com a cultivar Dover, em Santa Maria-RS, em cultivo hidropônico aberto, com sacolas plásticas contendo substrato orgânico comercial,

A produção (massa) de frutos por planta do sistema de cultivo em calhas foi significativamente superior à obtida no cultivo em sacos (Tabela 3). Tais diferenças muito provavelmente estão relacionadas à maior densidade de plantas e, consequentemente, maior competição entre plantas, no cultivo em sacos, em relação ao cultivo em calhas.

Tabela 3 - Massa de frutos por planta (g/planta) de quatro cultivares de morango em dois sistemas de cultivo hidropônico. Ibiapina-CE, 2012.

\begin{tabular}{|c|c|c|c|c|c|c|c|}
\hline Cultivares & Calhas & & Sacos & & & Média & \\
\hline Festival & 1407,0 & a $\mathrm{A}$ & 936,0 & $\mathrm{a}$ & B & 1171,5 & $\mathrm{a}$ \\
\hline Oso Grande & 1034,6 & b A & 809,8 & $\mathrm{a}$ & B & 922,2 & b \\
\hline Média & 1220,8 & $\mathrm{~A}$ & 872,9 & B & & 1046,9 & \\
\hline $\mathrm{CV}(\%)$ & 11,8 & & 9,6 & & & 11,3 & \\
\hline
\end{tabular}

Médias seguidas pelas mesmas letras minúsculas nas colunas e maiúsculas nas linhas não diferem entre si pelo teste $\mathrm{F}$ ao nível de $5 \%$ de probabilidade.

A cv. Festival apresentou maior massa de frutos de frutos por planta que a cultivar Oso Grande. A produtividade máxima por planta obtida no presente estudo com a cv. Festival cultivada em calhas (1407 g/planta) foi superior àquelas obtidas por Godoi et al. (2009) em cultivos hidropônicos fechados com a cultivar Arazá (1065 g/planta e $845 \mathrm{~g} / \mathrm{planta}$ em sacolas e em calhas, respectivamente). Oliveira et al. (2011) obtiveram produtividade de $774 \mathrm{~g} / \mathrm{planta}$ com a cv. Festival, em cultivo no solo na região de Pelotas-RS. Para sistemas de cultivo hidropônico em sacos, nas condições climáticas do Rio Grande do Sul, Bortolozzo et al. (2007) considera satisfatória uma produtividade média anual de $1200 \mathrm{~g} / \mathrm{planta}$.

\section{Massa média dos frutos}

O sistema de cultivo em calhas apresentou frutos de maior massa em relação ao sistema de sacos, o que pode ser atribuído à menor densidade de plantas utilizada naquele sistema (Tabela 4). A cv. Oso Grande apresentou frutos de massa significativamente maior que a cv. Festival.

Observou-se que os frutos de morango produzidos no presente estudo apresentaram valores de massa média inferiores aos observados com as mesmas cultivares nas regiões Sul e Sudeste do Brasil. Virmond e Resende (2006) obtiveram valores de massa média de frutos da cv. Oso Grande de 13,8 g/fruto em cultivo no solo, no estado do Paraná. Oliveira et al. (2011) obtiveram frutos com massa média de 24,9 g com a cv. Festival, em Pelotas-RS. Tais diferenças indicam que há necessidade de avaliar outras cultivares de morango que apresentem melhor adaptação às condições climáticas da região, assim como aperfeiçoar o sistema de cultivo, visando à obtenção de frutos com maior tamanho.

Tabela 4 - Massa média do fruto (g) de duas cultivares de morango em dois sistemas de cultivo hidropônico. Ibiapina-CE, 2012.

\begin{tabular}{|c|c|c|c|c|c|c|c|c|}
\hline Cultivares & Calhas & & & Sacos & & & Média & \\
\hline Festival & 9,6 & $\mathrm{~b}$ & $\mathrm{~A}$ & 9,4 & $\mathrm{~b}$ & $\mathrm{~A}$ & 9,5 & $\mathrm{~b}$ \\
\hline Oso Grande & 12,0 & $\mathrm{a}$ & A & 11,6 & $\mathrm{a}$ & A & 11,8 & $\mathrm{a}$ \\
\hline Média & 10,8 & A & & 10,4 & $\mathrm{~B}$ & & 10,6 & \\
\hline $\mathrm{CV}(\%)$ & 4,0 & & & 2,4 & & & 3,8 & \\
\hline
\end{tabular}

Médias seguidas pelas mesmas letras minúsculas nas colunas e maiúsculas nas linhas não diferem entre si pelo teste $\mathrm{F}$ ao nível de 5\% de probabilidade.

\section{Eficiência de utilização da água}

Durante o ciclo da cultura (274 dias) o consumo total de solução nutritiva foi maior no sistema de calhas em relação ao sistema de cultivo em sacos $(101 \mathrm{~L} /$ planta e $98 \mathrm{~L} /$ planta nos sistemas de calhas e de sacos, respectivamente). Essas diferenças, embora pequenas, podem ser atribuídas à menor densidade de plantio e às perdas de água por evaporação que ocorrem nas calhas e que são reduzidas nos sacos de cultivo, nos quais a superfície do substrato fica quase que totalmente coberta. 
No entanto, o sistema de calhas apresentou maior eficiência de utilização da água que o sistema de cultivo em sacos, em virtude da maior produtividade por planta (Figura 1). Foram observados valores médios de eficiência de utilização da água de 12,1 e 8,9 g de frutos por litro de solução nutritiva consumida, para os sistemas de cultivo em calhas e em sacos, respectivamente. Esses valores de eficiência de utilização da água foram superiores aos observados por Kirschbaum et al. (2004) em cultivos no solo $\left(4,0\right.$ a $\left.4,5 \mathrm{~g} \mathrm{~L}^{-1}\right)$.

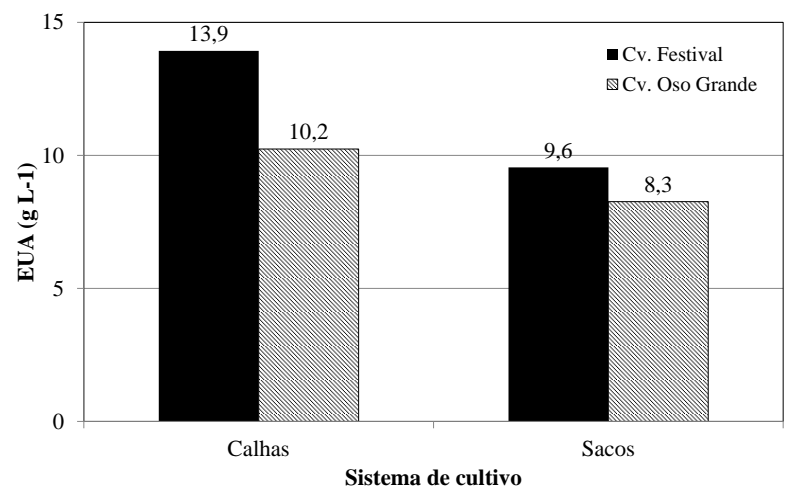

Figura 1 - Eficiência de utilização da água (EUA, em gramas de frutos por litro de solução nutritiva) das cultivares de morangueiro Festival e Oso Grande, em sistemas de cultivo hidropônico de calhas e de sacos. Ibiapina-CE, 2012.

Ressalta-se que os sistemas fechados como os utilizados no presente estudo apresentam uma redução do consumo de água e fertilizantes da ordem de $20 \%$ a $50 \%$ em relação aos sistemas hidropônicos abertos, nos quais se aplica um excesso de solução nutritiva para controlar a salinidade no substrato. Nesses sistemas, caso o volume excedente não seja aproveitado em outros cultivos, há redução da eficiência de utilização da água e nutrientes e poluição do solo e do lençol freático, razão pela qual alguns países tem proibido o uso de sistemas hidropônicos abertos.

\section{CONCLUSÕES}

1. Os sistemas hidropônicos fechados em calhas e em sacos, contendo substrato de fibra de coco apresentaram produtividades semelhantes de morango;

2. Nas condições climáticas da serra da Ibiapaba, a cv. Festival apresentou produtividade superior à cv. Oso Grande, que por sua vez apresentou frutos com maior massa.

3. Em termos de eficiência de utilização da água, os melhores resultados foram obtidos com o sistema hidropônico em calhas e a cultivar Festival.

\section{REFERÊNCIAS}

ANDRIOLO, J.L.; BONINI, J.V.; BOEMO, M.P. Acumulação de matéria seca e rendimento de frutos de morangueiro cultivado em substrato com diferentes soluções nutritivas. Horticultura Brasileira, v. 20, n. 1, p. 24-27, 2002. http://dx.doi.org/10.1590/S0102-05362002000100004

ANTUNES, L.E.C.; REISSER JÚNIOR, C. Fragole, i produttori brasiliani mirano all' esportazione in Europa. Rivista di Frutticoltura e di Hortofloricoltura, v. 69, p. 60-64, 2007.

BONNECARRÈRE, R.A.G. Soluções nutritivas e formas de manejo do morangueiro em hidroponia. Santa Maria, 2002. 55p. Dissertação (Mestrado em Agronomia) - Curso de Pós-graduação em Agronomia, Universidade Federal de Santa Maria.

BORTOLOZZO, A.R., SANHUEZA, R.M.V., MELO, G. W. B., BERNARDI, J. KOVALESKI, A., HOFFMANN, A., BOTTON, M., FREIRE, J. M., BRAGHINI, L.C., VARGAS, L., CALEGARIO, F. F., FERLA, N. J., PINENT, S. M. J. Produção de morangos no sistema semihidropônico. Circular Técnica, 62. Bento Gonçalves: Embrapa, 2007. 24 p.

CANSIAN, R. L.; MOSSI, A.J.; LEONTIEV-ORLOV, O.; BARBIERI, C.; MURTELLE, G.; PAULETTI, G.; ROTA, L. Comportamento de cultivares de morango (Fragaria $x$ ananassa Duch) 
na região do Alto Uruguai do Rio Grande do Sul. Revista Brasileira de Agrociência, v. 8, n. 2, p. 103-105, 2002.

CARRIJO, O.A.; VIDAL, M.C.; REIS, N.V.B.; SOUZA, R.B.; MAKISHIMA, N. Produtividade do tomateiro em diferentes substratos e modelos de casas de vegetação. Horticultura Brasileira, v. 22, n. 1, p.5-9, 2004. http://dx.doi.org/10.1590/S0102-05362004000100001

EMBRAPA Sistema de Produção do Morango: Cultivo Protegido. Embrapa Clima Temperado, Sistemas de Produção, 5. Versão Eletrônica, 2005. Disponível em: http://sistemasdeproducao.cnptia.embrapa.br/FontesHTML/Morango/SistemaProducaoMorango/in dex.htm. Acesso em: 24 jan 2012.

FERNANDES JÚNIOR, F.; FURLANI, P.R.; RIBEIRO, I.J.A.; CARVALHO C.R.L. Produção de frutos e estolhos de morangueiro em diferentes sistemas de cultivo em ambiente protegido. Bragantia, v.61, n.1, p.25-34, 2002. http://dx.doi.org/10.1590/S0006-87052002000100005

FURLANI, P.R.; FERNANDES JÚNIOR, F. Cultivo hidropônico de morango em ambiente protegido. In: SIMPÓSIO NACIONAL DO MORANGO \& ENCONTRO DE PEQUENAS FRUTAS E FRUTAS NATIVAS DO MERCOSUL, 2., 2004, Pelotas. Anais... Pelotas: Corrêa Antunez, L.E. et al. (Ed.). EMBRAPA, 2004. p.102-115. (Documentos 124).

GIMENEZ, G.; ANDRIOLO, J.L.; GODOI, R.S. Cultivo sem solo do morangueiro. Ciência Rural, v.38, n.1, p.273-279, 2008. http://dx.doi.org/10.1590/S0103-84782008000100048

GODOI, R.S.; ANDRIOLO, J.L.; FRANQUÉZ, G.G.; JÄNISCH, D.I.; CARDOSO, F.L.; VAZ, M. A.B. Produção e qualidade do morangueiro em sistemas fechados de cultivo sem solo com

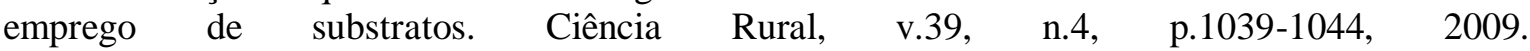
http://dx.doi.org/10.1590/S0103-84782009005000054

KIRSCHBAUM, D.S.; CORREA, M.; BÛRQUEZ, A.M.; LARSON, K.D.; DEJONG, T.M. Water Requirement and Water Use Efficiency of Fresh and Waiting-Bed Strawberry Plants. Acta Horticulturae, v.664, p.347-352, 2004.

NUNES, M.U.C. Produção de mudas de hortaliças com o uso da plasticultura e do pó de coco. Circular Técnica da Embrapa Tabuleiros Costeiros 13, Aracaju, 2000.

OLIVEIRA, R.P.; SCIVITTARO, W.B.; ROCHA, P.S.G. Produção de cultivares de morango, utilizando túnel baixo em Pelotas. Revista Ceres, v. 58, n.5, p. 625-631, 2011. http://dx.doi.org/10.1590/S0034-737X2011000500013

VIRMOND, M.F.R.; RESENDE, J.T.V. Produtividade e teor de sólidos solúveis totais em frutos de morango sob diferentes ambientes de cultivo. Revista Eletrônica Lato Sensu-Ciências Agrárias, v. 1, p. 62-69, 2006. 